\title{
Analiza podjetniškega podpornega okolja za startupe
}

\author{
Elvira Matko* \\ Gomile 21, 8321 Brusnice, Slovenija \\ elvira.matko@gmail.com
}

\begin{abstract}
Povzetek:
Raziskovalno vprašanje (RV): Kako razširjeno je podjetniško podporno okolje za startupe v Sloveniji v smislu geografije, števila različnih subjektov in vira financiranja?

Namen: Namen našega raziskovanja je, da ugotovimo razširjenost podjetniškega podpornega okolja oziroma ekeosistema za startupe v Sloveniji. Zanima nas, katera geografska področja podpore so pokrita, katere vrste subjektov podpornega okolja prevladujejo in kateri kapital jih ustanavlja.

Metoda: Za pridobivanje podatkov smo najprej pregledali obstoječo literaturo in spletne strani posameznih subjektov na področju poslovnega podpornega okolja za startupe. Pripravili smo seznam vseh subjektov in analizirali, katere aktivnosti podpornega okolja nudijo startupom.

Rezultati: Ugotovili smo, da je slovensko podjetniško podporno okolje za startupe na določenih geografskih območjih močnejše zastopano kot na drugih. Poleg tega večina podpornih subjektov ni specializirana za specifične potrebe start-upov, ampak pomaga tudi običajnim podjetjem, kar pomeni, da njihova podpora. Velika večina podpornih subjektov je bila ustanovljena z javnim denarjem, poleg tega tudi zasebni subjekti večino virov financiranja pridobijo iz javnih razpisov. Organizacija: Menimo, da bo naša raziskava pomagala subjektom podpornega podjetniškega okolja za startupe prepoznati kritična področja, ki jih je potrebno okrepiti, in s tem pomagala bodočim ustanoviteljem startupov do bolj učinkovite podpore $\mathrm{v} v$ seh fazah razvoja startupov.

Družba: Ekonomska aktivnost in ustanavljanje uspešnih podjetij imata velik vpliv na uspešnost družbe in njeno socialno okolje. Uspešna podjetja ljudem omogočajo dostojno življenje in uresničitev potencialov. Startup podjetja predstavljajo velik potencial za rast in razvoj.

Originalnost: Menimo, da je naloga originalna $\mathrm{v}$ dveh vidikih. Podaja analizo subjektov slovenskega podpornega podjetniškega okolja, pri čemer smo raziskali nekatere nove dejavnike in $\mathrm{s}$ tem pridobili nov pogled na tematiko. Po drugi strani, pa je našla luknje v obstoječem stanju, ki ustanoviteljem startupov otežujejo delo.

Omejitve/nadaljnje raziskovanje: Raziskava je zaradi svoje obsežnosti omejena samo na Slovenijo in njeno podporno podjetniško okolje. Poleg tega je bilo pridobivanje podatkov omejeno na pregledovanje spletnih strani in objav ter ni bilo osebno preverjeno za vsak subjekt
\end{abstract}

Ključne besede: startup, podporno okolje, podporni ekosistem, podjetništvo, Slovenija, inkubator, tehnološki park, coworking.

\section{Uvod}

Podjetništvo velja za eno izmed gonilnih sil razvoja gospodarstva in družbe. Zato poskušajo države čim bolj spodbujati podjetništvo in odstranjujejo administrativne ovire za ustanavljanje podjetij. Ustanovitev podjetja še nikoli ni bila tako enostavna. Tako je možno v Sloveniji 
ustanovitvi s.p. $\mathrm{v}$ enem samem dnevu kar iz domačega naslonjača. Vendar je ustanovitev podjetja šele prvi korak k podjetništvu. Pogosto posameznik ustanovi s.p., zato da bo opravljal določeno dejavnost, njegov cilj ni rast in zaposlovanje ljudi, ampak ustvariti določen mesečen dohodek, ki bo njemu in njegovi družini omogočal preživetje.

Na drugi strani imamo posameznike in time, ki imajo idejo, kako rešiti določen problem, s katerim se spopada veliko ljudi, in zato ustanovijo podjetje, ki bo imelo velik potencial za rast. Če uspejo, taka podjetja ustvarijo relativno veliko delovnih mest $\mathrm{z}$ visoko dodano vrednostjo ter $\mathrm{s}$ tem prispevalo $\mathrm{k}$ bruto domačemu proizvodu ter blaginji države in njenih državljanov. V zadnjih letih so taka podjetja tako priljubljena, da so dobila posebno ime. V angleščini jim rečemo start-up. Ta izraz se je uveljavil tudi v slovenščini, uporablja se tudi izraz zagonsko podjetje ali inovativno visokotehnološko podjetje .

Podjetniki v začetni fazi, ko poskušajo uresničiti svoje ideje in ustanoviti podjetje ter ga plasirati na trg, potrebujejo ustrezno pomoč, sicer težko uspejo, zato se je razvilo podporno okolje za podjetništvo. Vendar se potrebe zagonskih podjetij razlikujejo od običajnih podjetij in temu primerno se je razvilo tudi specifično podporno okolje, ki jim je namenjeno. Veliko je na tem področju naredila država in občine, po drugi strani pa je vedno več tudi podpornih institucij, ki so financirane z zasebnim kapitalom.

Raziskati želimo podporno okolje za zagonska podjetja v Sloveniji. Želimo odkriti, katera področja niso zadostno zastopana in kakšne možnosti obstajajo za izboljšave. S tem namenom bomo izvedli analizo za kateri tipi podpornih subjektov so zastopani, na katero geografsko regijo so omejeni, ali gre za javne ali zasebne institucije ter kateri vrsti podjetij nudijo podporo - samo start-upom ali tudi običajnim podjetjem. Glede na prvi pregled pričakujemo, da je večina institucij, ki podpirajo zagonska podjetja, javnega značaja, zasebne so v Sloveniji v manjšini. Geografsko po našem mnenju prevladujejo podporne institucije v osrednji slovenski regiji oziroma Ljubljani.

\section{Teoretična izhodišča}

Rebernik in Jaklič (2014, str. 10) ugotavljata, da je podjetniško podporno okolje v Sloveniji že do določene mere razvito. Razvoj se je začel pred dobrimi 25 leti, vendar je bil zastavljen na splošno in usmerjen na vse podjetnike, pri čemer se ni upoštevalo, da podjetniško strukturo tvorijo zelo raznoliki podjetniki, od samozaposlenih posameznikov, malih podjetij, rastočih podjetij, velikih podjetij itd. Ti podjetniki imajo zelo različne ambicije, različno prispevajo $\mathrm{k}$ razvoju in pri njih obstajajo velike razlike pri tem kakšne spodbude potrebujejo. Podpora visokotehnoloških podjetjem s potencialom hitre rasti ima številne specifike v primerjavi z ostalimi skupinami podjetnikov, zato se je v svetu že ločila od podpore splošnega podjetništva. V Sloveniji pa nerazumevanje razlik ovira zasnovo primerne podjetniške politike in izgradnjo učinkovitih mehanizmov podpore za vsak tip podjetnikov. Stat-up podjetja imajo potencial, da največ prispevajo $\mathrm{k}$ rasti, zaposlovanju in razvoju, zato je potrebno podjetniško politiko v Sloveniji zasnovati na tak način, da jim bo nudila podporno 
okolje skozi vse faze razvoja start-up podjetja. Po mnenju Rebernika in Jakliča (2014, str. 910) je prišlo do vidnega napredka v razvoju podpornega okolja v Sloveniji pa letu 2012, ko se je povečalo tako število novih podpornih institucij kot tudi projektov in vključenih podjetnikov.

Za vzpostavitev uspešnega podpornega okolja za inovativno podjetništvo potrebujemo po mnenju Rebernika in Jakliča (2014, str. 10-11) naslednje elemente:

- Dvigniti raven podjetniškega aktiviranja talentov za povečanje števila inovativnih start-up podjetij. Pri tem velik pomen igrata šolski sistem in širši sistem vzgoje za podjetništvo.

- Komercializacija znanja in tehnologij, kar pomeni, da podjetniki gradijo svoja podjetja na osnovi povezav z raziskovalno-razvojnimi dosežki in idejami, ki nastajajo v okviru izobraževalnih institucij in drugih podjetij.

- S svojimi povezavami po svetu spodbujati rast podjetij na svetovnih trgih. Uspeh na svetovnih trgih namreč zagotavlja možnost izgradnje vplivnega in finančno zelo uspešnega podjetja.

- Prispevati k večji dostopnosti kapitala, saj je pomanjkanje kapitala ena od ključnih ovir za rast in razvoj start-up podjetij. Kapital mora biti na voljo v vseh fazah razvoja in predstavljati predvsem kapitalske investicije in $\mathrm{v}$ dosti manjši meri dolžniški kapital.

- Aktiviranje različnih deležnikov ekosistema, ki morajo svojo vlogo odigrati čim bolj aktivno in koordinirano. Vodenje podpornega okolja mora biti usklajeno, celostno in strateško, saj lahko že samo pomanjkanje nekaj delov ekosistema pomembno zavre učinke start-up ekosistema.

Zakonsko je v Sloveniji podjetniško podporno okolje urejeno z Zakonom o podpornem okolju za podjetništvo (ZPOP-1), ki je začel veljati konec leta 2007. Cilj zakona je vzpostavitev podpornega okolja na nacionalni ravni, povečanje možnosti za ustanavljanje novih podjetij, spodbuditev izkoriščanja podjetniških in inovacijskih potencialov ter spodbuditev povezovanja med gospodarstvom in raziskovalnimi ter izobraževalnimi ustanovami. (ZPOP1).

Na podlagi tretjega odstavka 11. člena Zakona o podpornem okolju za podjetništvo je bil izdan Pravilniku o vodenju evidence subjektov inovativnega okolja, ki je stopil v veljajo leta 2008, vendar je bil leta 2017 razveljavljen. Pravilnik je definiral pojme inovativnega okolja ter določil pogoje za vpis v evidenco subjektov inovativnega okolja. Pogosto je bil pogoj za sodelovanje na javnih razpisih za finančne vire, da je bil subjekt vpisan v evidenco. Razveljavljeni 14. člen ZPOP-1 je definiral, da morajo subjekti inovativnega okolja izvajati promocijo inovativnosti in inovativne kulture, morajo iskati nosilce novih poslovnih idej in izvajati storitve za prepoznavanje in razvoj teh idej do stopnje za njihovo realizacijo, morajo zagotavljati ugodne prostorske in tehnične pogoje za nastajanje in delovanje teh podjetij ter 
izvajati podporo razvoju podjetij od ideje do ustanovitve ter začetnega delovanja podjetij pod ugodnejšimi pogoji (ZPOP-1, 14. člen).

V literaturi obstajajo različne definicije subjektov podpornega okolja (Allen \& Rahman, 1985; Campbell, 1989 in Lah, 2009), mi bomo zaradi večje jasnosti povzeli definicije, ki jih je definiral že prej omenjeni Pravilnik o vodenju evidence subjektov inovativnega okolja (2008, 3. člen), ki kot subjekte podpornega okolja vodi naslednje: univerzitetni inkubatorji, podjetniški inkubatorji in tehnološki parki.

Podjetniški inkubator je Pravilnik (2008) definiral kot »institucijo, ki v prostorih na določeni lokaciji omogoča učinkovito nastajanje in razvoj novih podjetij in zagotavlja urejeno poslovno okolje $\mathrm{z}$ infrastrukturo in $\mathrm{s}$ širšim naborom upravnih in intelektualnih storitev $\mathrm{za}$ inovativna podjetja.«

Pravilnik (2008) je univerzitetni inkubator definiral kot institucijo, ki je povezana $\mathrm{z}$ univerzo ali visokošolskim zavodom in omogoča realizacijo podjetniških pobud predvsem dijakov, študentov in profesorjev. Poleg tega nudi podporo inovativnim tehnološkim podjetjem in poslovnim zamislim.

Pravilnik (2008) je tehnološki park definiral kot »institucijo, ki na prostorsko koncentrirani večji lokaciji združuje razvojno raziskovalne in poslovne dejavnosti novih inovativnih tehnoloških podjetij in razvojno raziskovalnih (R\&R) oddelkov podjetij. Tehnološki park omogoča nastajanje novih inovativnih tehnoloških podjetij in s tem nudi urejeno poslovno okolje s širšim naborom podpornih, upravnih in intelektualnih storitev za ta podjetja.«

Pravilnik (2008) je inkubirance definiral kot »inovativno podjetje ali posameznik kot nosilec poslovne zamisli ki je vpisan manj kot pet let $\mathrm{v}$ ustrezen register in je vključen $\mathrm{v}$ posamezen subjekt, uporablja storitve in infrastrukturo subjekta in $\mathrm{z}$ njim pogodbeno urejen odnos, ter hkrati ni povezano podjetje $\mathrm{z}$ subjektom ali velikim podjetjem $\mathrm{v}$ smislu predpisov, ki urejajo gospodarske družbe.«

Rebernik in Jaklič (2014, str. 11) menita, da imamo v Sloveniji sicer delno postavljeno podporno okolje za start-up podjetništvo, vendar mnoga področja sploh niso pokrita oziroma niso pokrita $v$ zadostni meri. Potrebno je organizirati dosti več aktivnosti, jih kakovostno izboljšati ter predvsem ustrezno povezati, da bodo nudila start-up oziroma inovativnim podjetjem celoviti podporo $v$ vseh fazah razvoja.

Če želimo to doseči, potrebujemo najprej dober pregled subjektov podpornega okolja za startup podjetništvo, pri čemer se je potrebno osredotočiti na različne vidike. Prvi sistematičen pregled slovenskega start-up okolja je pripravila organizacija InternetWeek. Pregled je predstavljen v obliki Coggle diagrama, ki je pravzaprav digitalni miselni vzorec, kar omogoča, da vsebuje tudi hiperpovezave na vse elemente. Spodaj povzetek najpomembnejših elementov slovenskega startup okolja s primeri (Pirnat, 2014): 
- dogodki, ki se delijo na naslednje elemente:

○ konference in festivali (npr. StartUp festival, SOF, PODIM, Startup Crawl)

○ tekmovanja (npr. Mladi podjetnik leta, Gazela, Startup leta, Startup weekend, Diggit)

○ ciklični dogodki (npr. StartUP Story, TEDX Ljubljana, Startup cafe, Start:up Müsli)

○ pregledi dogajanja (Skupni koledar, Internet Weekly, Novičnik)

- mediji, ki se delijo na naslednje elemente:

○ tiskani mediji (npr. Preboj, Finance, Gazela)

- spletni mediji (npr. Tromba, Startaj.si, Mladi podjetnik)

○ blogi (npr. Aleš Špetič - Glasnik digitalnih tehnologij, Anže Tomoć Apparatus)

○ družabni mediji (Twitter, Foursquare)

- Facebook skupine (npr. Silicon gradens, Ljubljana Startup, Lean startup, Delaj vitko)

- financiranje, ki vključuje naslednje elemente:

○ angelski investitorji (npr. Jugoslav Petković, Branko Drobnak itd.)

○ subvencije (podjetniški sklad)

○ skladi tveganega kapitala (RSG Capital, Silicon Gardens Angel Fund)

- združenja in infrastruktura:

○ javni sektor (npr. Enterprise, SPIRIT Slovenija)

○ podjetniške organizacije (SKIS, CEED, Silicon gardens)

○ tehnološki parki (npr. Tehnološki park Ljubljana, Pomurski tehnološki park, RCIKT Kranj)

o inkubatorji (npr. Inkubator Sežana, Tovarna podjemov, Regionalni center za razvoj Zasavje, Podjetniški inkubator Podbreznik)

○ pospeševalniki (DsgnFWD, StartUP NM)

- izobraževanje, ponudniki storitev in zaposlitvene možnosti:

○ izobraževanje: npr. Tehnološki park Ljubljana, Hekovnik, Kiberpipa, Delaj vitko, Ustvarjalnik

○ ponudniki storitev: npr. Startup Garaža, Geekhouse, Mladi podjetnik, Coworking Podbreznik Novo mesto

○ zaposlitvene možnosti: StartupJob.si

Kot osnovo za našo raziskavo smo vzeli pregled obstoječih inkubatorjev, tehnoloških parkov, pospeševalnikov in deljenih prostorov v Sloveniji, ki ga je v sklopu svoje magistrske naloge pripravila Rožič (2017) in je prikazan v tabeli 1. Kljub temu, da je pregled relativno nov, je v vmesnem času prišlo do določenih sprememb oziroma so določeni subjekti manjkali. Seznam coworking prostorov smo nadgradili na podlagi članka Veliki seznam coworking prostorov v Sloveniji (Rožanc, 2019). Poleg tega smo našli še nekaj subjektov v evidenci Pravilnika o vodenju evidence subjektov inovativnega okolja (2008) ter pri brskanju po spletu. 
Tabela 1. Pregled obstoječih inkubatorjev, tehnoloških parkov, pospeševalnikov in deljenih prostorov v Sloveniji

\begin{tabular}{|c|c|c|}
\hline Inkubatorji & $\begin{array}{l}\text { Tehnološki parki in } \\
\text { pospeševalniki }\end{array}$ & $\begin{array}{l}\text { Deljeni (angl. coworking) } \\
\text { prostori }\end{array}$ \\
\hline $\begin{array}{l}\text { - } \text { Inkubator Sežana } \\
\text { - } \text { Ljubljanski univerzitetni } \\
\text { inkubator } \\
\text { - Mrežni podjetniški } \\
\text { inkubator Ormož } \\
\text { - } \text { Podjetniški inkubator } \\
\text { Podbreznik } \\
\text { - } \text { Podjetniški inkubator } \\
\text { Kočevje } \\
\text { - Podjetniški inkubator } \\
\text { Kostel } \\
\text { - Smart:up Incubator } \\
\text { - Kranj } \\
\text { - Socialni inkubator } \\
\text { - } \text { Tovarna podjemov } \\
\text { center in inkubator } \\
\text { Primorske } \\
\text { - Univerzitetni inkubator } \\
\text { savinjske regije } \\
\text { Zavod znanje Postojna }\end{array}$ & $\begin{array}{ll}\text { - } & \text { Pomurski tehnološki park } \\
\text { - } & \text { Primorski tehnološki park } \\
\text { - } & \text { Razvojni center za } \\
\text { informacijske in } \\
\text { komunikacijske } \\
\text { tehnologije Kranj } \\
\text { (RCIKT) } \\
\text { - Štajerski tehnološki park } \\
\text { - Tehnološki park Ljubljana } \\
\text { - Tehnološko razvojni } \\
\text { center za Koroško }\end{array}$ & $\begin{array}{ll}\text { - } & \text { Aurora Coworking } \\
\text { - } & \text { Coworska Sobota } \\
& \text { Novo mesto } \\
\text { - } & \text { Coworking Zasavje } \\
\text { - } & \text { Geekhouse } \\
\text { - } & \text { Little Soho } \\
\text { - } & \text { Mladi podjetnik } \\
\text { - } & \text { Poligon kreativni } \\
& \text { center } \\
\text { - } & \text { Startup Garaža }\end{array}$ \\
\hline
\end{tabular}

Povzeto iz: N. Pirnat, Startup ekosistem v Sloveniji, 2014; Evidenca subjektov inovativnega okolja, 2016; Pospeševalniki, 2017

Glede na pregled teorije, smo postavili naslednje teze:

(T1) Podjetniško podporno okolje za start-upe je najbolj razvito v Osrednji Sloveniji oziroma Ljubljani.

(T2) Večina subjektov podjetniškega podpornega okolja je ustanovljena s strani javnih institucij.

(T3) Večina subjektov podjetniškega podpornega okolja deluje na področju start-upov oziroma inovativnih podjetij.

\section{Metoda}

Podatke smo zbirali v obstoječi literaturi in na spletu. Najprej smo pregledali obstoječo literaturo in spletne strani posameznih subjektov na področju podpornega poslovnega okolja za startupe. S kombinacijo različnih virov smo pripravili seznam vseh subjektov. Pri pregledu 
literature smo se osredotočili na novejše publikacije, ker se stanje na področju subjektov podpornega okolja zelo hitro spreminja, tako da smo iskali smo literaturo od leta 2010 naprej.

Ker raziskujemo podporno okolje v Sloveniji, smo opravili pregledu literature v COBISS-u (iskali smo po vseh gradivih in vseh knjižnicah, objave so morale biti iz 2010 ali novejše), pri tem smo uporabili naslednje ključne besede: podporno okolje, inkubator, pospeševalnik, tehnološki park in co-working prostor. Ugotovili smo, da je večina najdenih publikacij, diplomskih, magistrskih, raziskovalnih del in da so tiskane knjige na teh področjih zelo redke in še te, ki smo jih našli, niso relevantne za našo nalogo. Posledično smo se osredotočili na spletne vire, saj smo ugotovili, da je na področju podpornega poslovnega okolja za start-upe v Sloveniji večina virov spletnih.

Pripravili smo tudi model raziskave subjektov podjetniškega podpornega okolja v Sloveniji, ki je prikazan na sliki 1. Najprej smo najprej pripravili seznam subjektov s pomočjo pregleda tiskanih in spletnih publikacij. Nato smo identificirali dejavnike, ki jih je smiselno raziskovati in analizirati. Iz seznama subjektov in dejavnikov smo pripravili preglednico, ki nam je bila $\mathrm{v}$ pomoč pri izvedbi analize. Analizo podatkov smo začeli s tem, da smo ocenili za katere dejavnike, ki smo jih raziskovali, imamo dovolj relevantnih podatkov za analizo. Analizo smo nato izvedli samo za te dejavnike. Sledilo je še komentiranje rezultatov analize. 


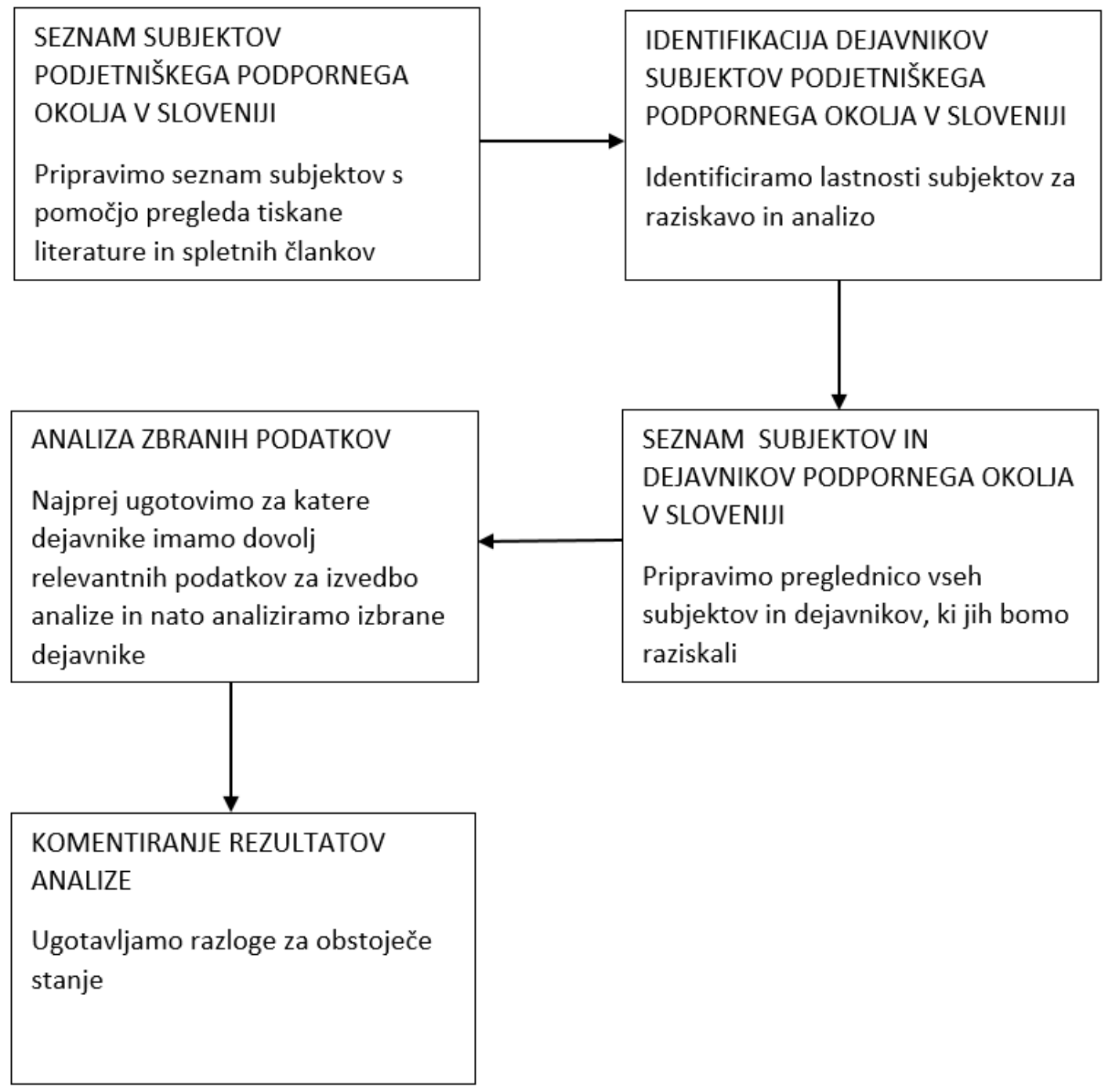

Slika 1. Grafični prikaz modela raziskave

Nato smo glede na dostopne podatke na spletnih straneh subjektov in spletni strani Agencije Republike Slovenije za javnopravne evidence in storitve (AJPES) naredili analizo. Subjekte smo analizirali glede na vrsto (tehnološki park, inkubator, pospeševalnik in coworking), glede na regijo (Osrednjeslovenska oz. Ljubljana, Gorenjska, Dolenjska, Primorska \& Notranjska (ločeno Goriška), Štajerska (ločeno Koroška) in Prekmurje, glede na vrsto ustanoviteljev (javni, javno-zasebni in zasebni) ter glede na to ali nudijo podporo samo start-upom ali tudi običajnim podjetjem.

Pri analizi smo se soočili z določenimi omejitvami, saj večina podatkov, ki smo jih raziskovali za coworking prostore ni bila na voljo ali pa niso relevantni za njih, zato smo jih $\mathrm{v}$ takih primerih izločili iz analize. Poleg tega niso bili vedno na voljo tudi vsi podatki za tehnološke parke in inkubatorje ali so se podatki na spletni strani in evidenci AJPES razlikovali. 


\section{Rezultati}

Podjetniško podporno okolje vsebuje različne vrste subjektov, tako da smo subjekte podpornega okolja najprej analizirali glede na vrsto: tehnološki park, inkubator, pospeševalnik in coworking prostor.

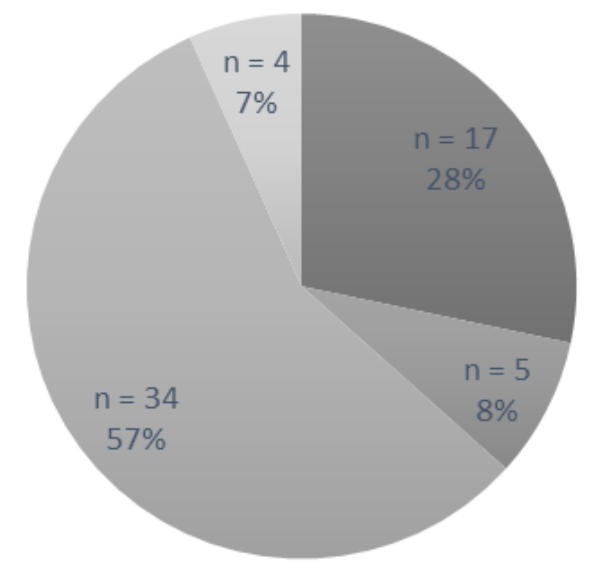

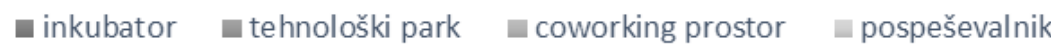

Slika 2. Število subjektov podjetniškega podpornega okolja glede na vrsto subjekta

Izmed subjektov podjetniškega podpornega okolja je $57 \%$ oziroma 34 coworking prostorov, $28 \%$ oziroma 17 inkubatorjev, $8 \%$ oziroma 5 tehnoloških parkov ter $7 \%$ oziroma 4 pospeševalniki.

Nadalje smo raziskovali razširjenost subjektov podjetniškega podpornega okolja glede na regijo (T1 - Podjetniško podporno okolje za start-upe je najbolj razvito v Osrednji Sloveniji oziroma Ljubljani). Slovenijo smo razdelili glede na tradicionalne pokrajine: Osrednjeslovenska oz. Ljubljana, Gorenjska, Dolenjska, Primorska \& Notranjska, Štajerska in Prekmurje. Ker smo pri Štajerski in Primorski regiji opazili, da obstajajo zelo velike razlike pri različnih delih regije, smo uvedli dodatno razdelitev. Iz Primorske regije smo izločili statistično regijo Goriško in iz Štajerske statistično regijo Koroško. 


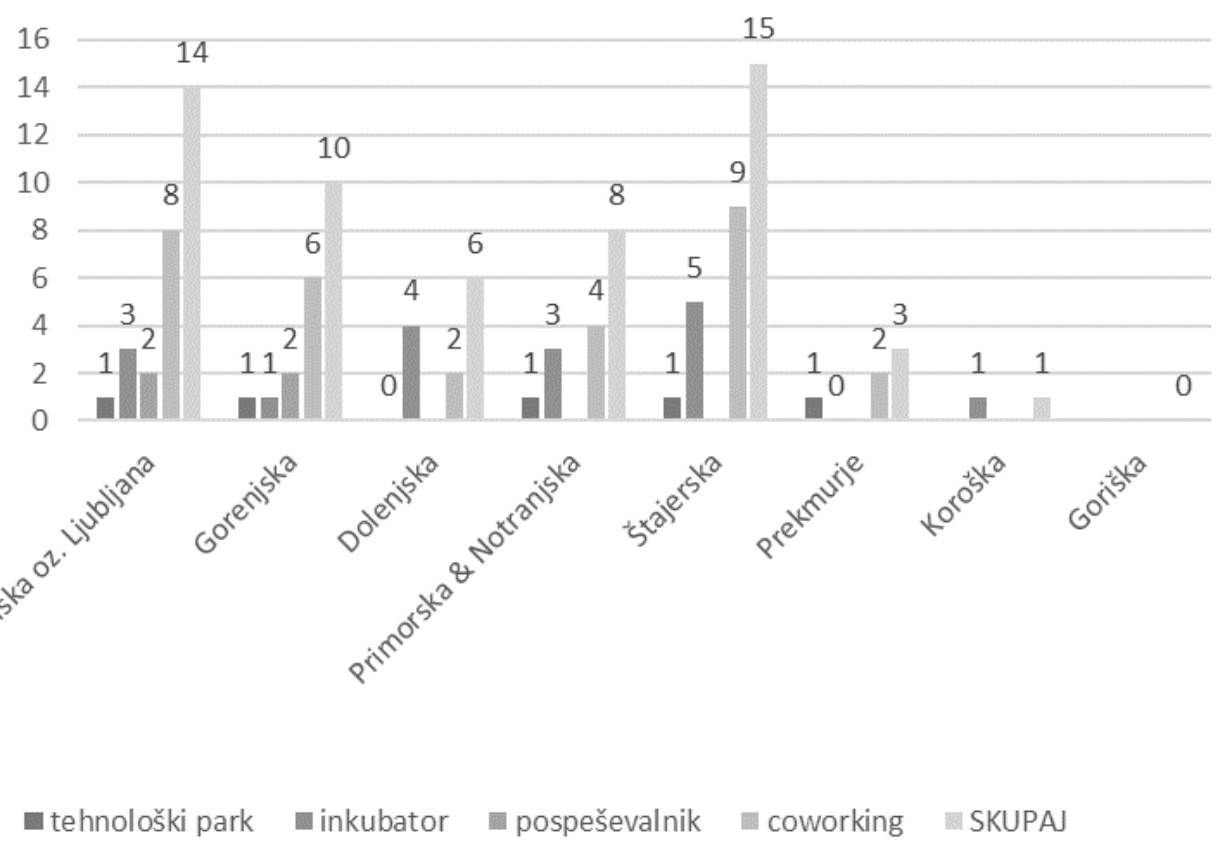

Slika 3. Število subjektov podjetniškega podpornega okolja glede na regijo

Regija z največ subjekti podjetniškega podpornega okolja je Štajerska (15), druga je osrednjeslovenska regija oz. Ljubljana s 14 subjekti, tretja je Gorenjska regija z 10 subjekti, sledi Primorska in Notranjska z osmimi subjekti, Dolenjska s šestimi subjekti, Prekmurje s tremi subjekti ter Koroška z enim subjektom.

Sledi analiza števila subjektov podjetniškega podpornega okolja glede na vrsto ustanovnega kapitala subjektov podjetniškega podpornega okolja (T2 - Večina subjektov podjetniškega podpornega okolja je ustanovljena s strani javnih institucij). Razdelili smo jih na naslednje skupine: javno, univerza, javno-zasebno ter zasebni.

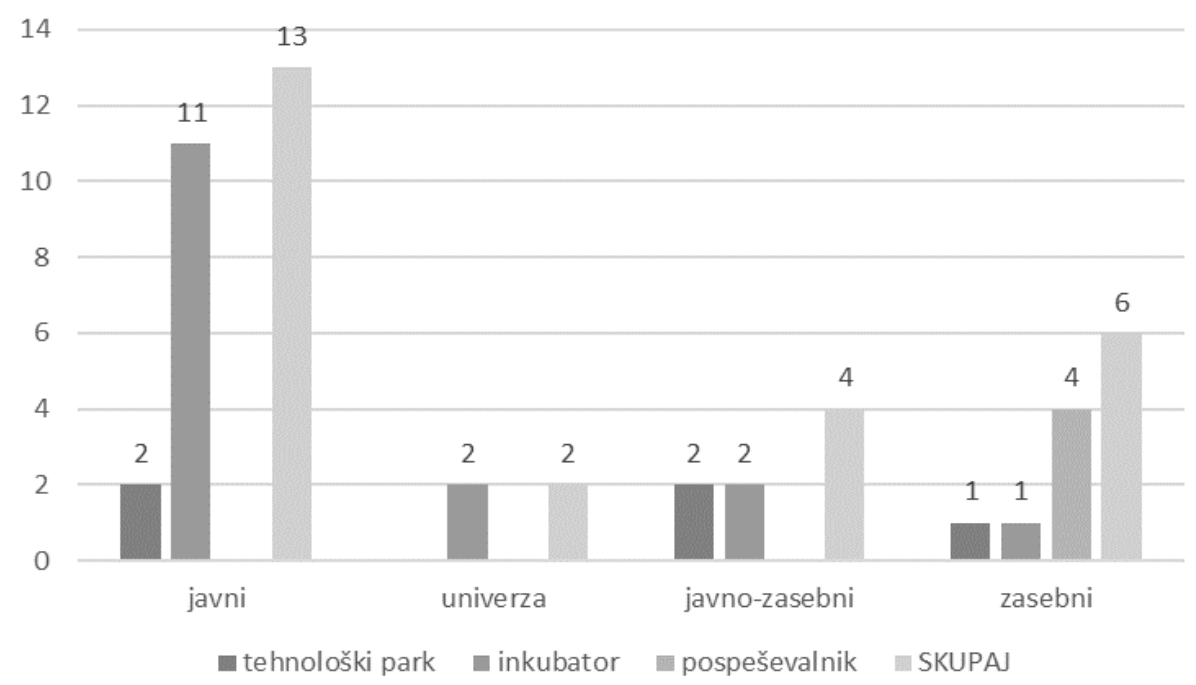

Slika 4. Število subjektov podjetniškega podpornega okolja glede na vrsto ustanovnega kapitala (javni vs. zasebni) 
Opažamo, da je delež zasebnega kapitala v subjektih podjetniškega podpornega okolja za startupe zelo majhen. Velika večina subjektov je ustanovljenih s strani javnih institucij, predvsem občin (13 subjektov), dva sta ustanovljena s strani univerze, štirje so javno-zasebno partnerstvo, šest pa jih ima zasebne ustanovitelje.

Nazadnje smo analizirali subjekte podjetniškega podpornega okolja glede na vrsto podjetij, ki so vključena $\mathrm{v}$ njih (T3 - Večina subjektov podjetniškega podpornega okolja deluje na področju start-upov oziroma inovativnih podjetij). Subjekte smo razdelili na tiste, ki vključujejo samo start-upe, tiste, ki vključujejo start-upe in običajna podjetja in tiste, ki vključujejo samo običajna podjetja, ki vsaj po našem mnenju niso inovativna in nimajo potenciala za veliko rast.

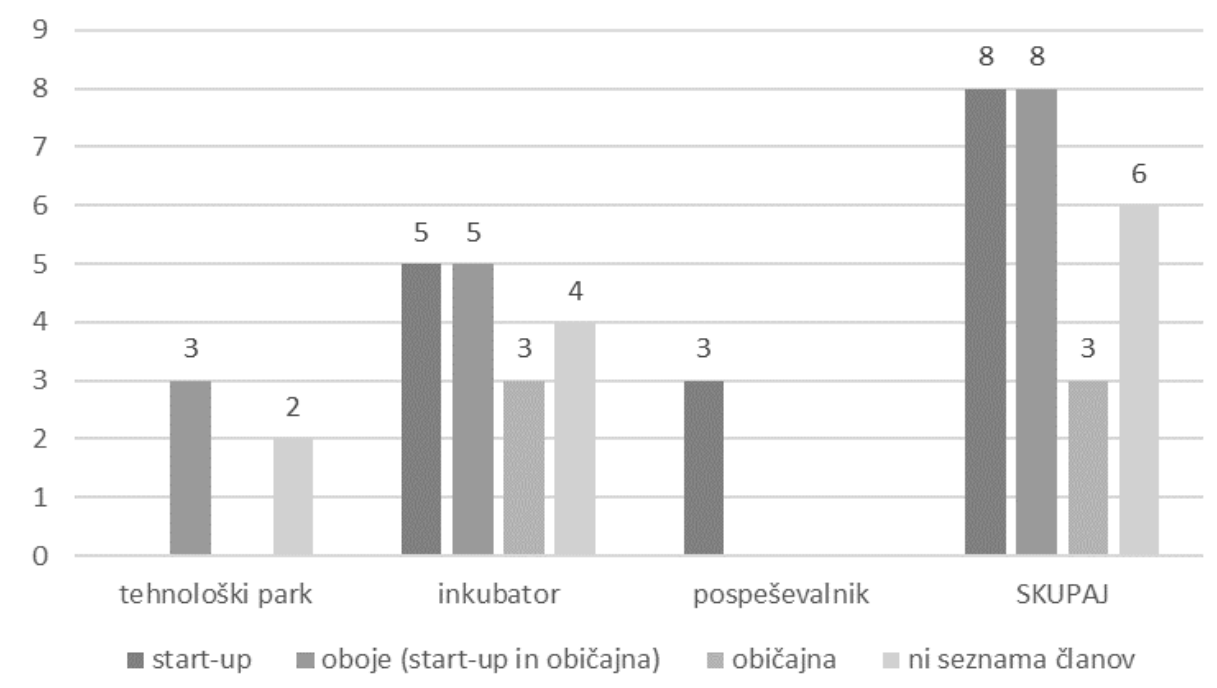

Slika 5. Število subjektov podjetniškega podpornega okolja glede na vrsto podjetij, ki jih podpirajo (start-upi ali običajna podjetja)

Izmed subjektov podjetniškega podpornega okolja ima 8 subjektov med člani oziroma inkubiranci samo start-up podjetja, 8 subjektov ima med člani oziroma inkubiranci start-up podjetja in običajna podjetja, pri 3 subjektih podjetniškega podpornega okolja pa samo bili člani samo običajna podjetja. Za 6 subjektov nismo našli podatkov.

\section{Razprava}

Glede na vrsto subjektov podjetniškega podpornega okolja imamo naslednjo porazdelitev: $57 \%$ oziroma 34 coworking prostorov, $28 \%$ oziroma 17 inkubatorjev, $8 \%$ oziroma 5 tehnoloških parkov ter $7 \%$ oziroma 4 pospeševalniki. Glede razširjenost subjektov podjetniškega podpornega okolja je regija z največ subjekti Štajerska (15), druga je osrednjeslovenska regija oz. Ljubljana s 14 subjekti, tretja je Gorenjska regija z 10 subjekti, sledi Primorska in Notranjska z 8 subjekti, Dolenjska s 6 subjekti, Prekmurje s 3 subjekti ter Koroška z 1 subjektom. Glede na vrsto ustanovnega kapitala (javni vs. zasebni) je velika večina subjektov ustanovljenih s strani javnih institucij, predvsem občin (13 subjektov), dva sta ustanovljena s strani univerze, štirje so javno-zasebno partnerstvo, šest pa jih ima zasebne 
ustanovitelje. Glede na vrsto podjetij, ki jih subjekti podpirajo (start-upi ali običajna podjetja), smo ugotovili, da ima 8 subjektov med člani oziroma inkubiranci samo start-up podjetja, 8 subjektov ima med člani oziroma inkubiranci start-up podjetja in običajna podjetja, pri 3 subjektih podjetniškega podpornega okolja pa samo bili člani samo običajna podjetja. Za 6 subjektov nismo našli podatkov.

Opažamo, da so daleč najbolj zastopani coworking prostori, kar je razumljivo, saj je za njihov nastanek potrebna daleč najmanjša investicija $\mathrm{v}$ smislu financ in časa ter ni potrebna registracija podjetja. Po drugi strani tudi veliko tehnoloških parkov in inkubatorjev ponuja coworking prostore. Opažamo, da kar nekaj coworking prostorov ponuja tudi dodatne storitve poleg samega prostora in po našem mnenju obstaja možnost, da bi se nadgradili na inkubatorje. Število coworking prostorov je v zadnjih letih zelo naraslo, saj obstaja zelo velika razlika v pregledu, ki ga je 2014 pripravila Pirnat (2014) in leta 2019 Rožanc (2019). Na seznamu iz leta 2014 je 8 coworking prostorov, na seznamu iz leta 2019 pa 31 coworking prostorov.

Opažamo, da so druga kategorija inkubatorji, nekaj pa je tudi pospeševalnikov. Po drugi strani pa imajo inkubatorji in pospeševalniki podobno funkcijo. Tretja kategorija so tehnološki parki, ki zahtevajo največ sredstev, od finančnih do prostora itd. Porazdeljeni so po regijah.

Opažamo, da nekateri deli Slovenije v podjetniškem podpornem okolju sploh niso zastopani oziroma samo z enim subjektom. Tako je na Koroškem samo en subjekt podjetniškega podpornega okolja - inkubator, ni prisotnega nobenega coworking prostora. Poleg tega ni zastopana goriška regija, čeprav ima kar nekaj za slovenske razmere relativno velikih mest in občin, to velja tako za subjekte podpornega okolja kot tudi coworking prostore. Glede na to, da večino subjektov podpornega okolja ustanovijo občine, to kaže, da imajo v teh občinah druge prioritete ali ne dajejo pomena visokotehnološkemu podjetništvu. Zaskrbljujoče je predvsem to, da sta to dve področji v Sloveniji, ki sta prometno slabo povezani z osrednjo Slovenijo, kjer se nahaja največ subjektov podpornega okolja, kar pomeni, da imajo prebivalci teh območij zelo težak dostop do podjetniškega podpornega okolja.

Ugotovili smo, da je velika večina subjektov podjetniškega podpornega okolja ustanovljena s strani javnih institucij. Tudi subjekti, ki so ustanovljeni s strani zasebnih institucij se v veliki meri financirajo iz javnih razpisov, zato menim, da bi bilo potrebno bolj natančno spremljati in poskusiti meriti kako so subjekti podjetniškega podpornega okolja učinkoviti. Pri tem ne mislim samo spremljanje koliko delavnic so izvedli ali koliko članov imajo, temveč predvsem ali njihovo delo prinaša konkretne učinke pri spodbujanju podjetništva in posledično bolj uspešna podjetja, ki ustvarjajo več delovnih mest in pomembno prispevajo k bruto domačemu proizvodu in s tem blaginji države in njenih državljanov.

Ugotovili smo, da dosti subjektov podjetniškega podpornega okolja »servisira« tako običajna podjetja kot start-upe. Glede na to, da imajo start-upi posebne potrebe, ki se razlikujejo od običajnih podjetij, obstaja velika verjetnost, da podpora v takih okoljih ni optimalna za start- 
upe. Po drugi strani pa se moramo zavedati, da je Slovenija relativno majhna država z manjšo gostoto prebivalstva in ustanavljanje specifičnih start-up subjektov podpornega okolja v vsaki regiji, verjetno ne bi doseglo svojega namena, saj ni zadosti potencialnih podjetij, ki bi jih ti subjekti lahko vključili. Še najbolj so se za start-upe specializirali pospeševalniki, ki so v zasebnih lasti, kar je razumljivo, saj si lahko sami izbirajo področja delovanja, za razliko od javnih subjektov, ki jim naloge nalagajo občine (ali druge javne institucije), ki so njihove ustanoviteljice.

Pri preverjanju tez smo prišli do naslednjih ugotovitev:

V naši analizi števila subjektov glede na regijo smo kot regijo z največ subjekti podjetniškega podpornega okolja identificirali Štajersko s 15 subjekti, Ljubljana ima samo enega manj, 14. Nato s kar precejšnjim zaostankom sledijo preostale regije. Menim, da glede na tesen rezultat teze T1 (Podjetniško podporno okolje za start-upe je najbolj razvito v Osrednji Sloveniji oziroma Ljubljani) ne moremo potrditi. Potrebno bi bilo narediti bolj podrobno analizo vrste subjektov in obsega podpore, ki jo nudijo.

Teza T2 (Večina subjektov podjetniškega podpornega okolja je ustanovljena s strani javnih institucij) drži, saj smo $\mathrm{v}$ naši raziskavi ugotovili, da je bila velika večina subjektov ustanovljenih s strani javnih institucij, če vključimo univerze je 15 subjektov ustanovljenih samo s strani javnih institucij, občutno manj jih je javno-zasebno partnerstvo (4) ali imajo zasebne ustanovitelje (6). Glede na našo analizo tudi institucije, ki so bile ustanovljene s strani zasebnega kapitala, večino svojih dejavnosti opravljajo s financiranjem iz javnih razpisov. Torej je v Sloveniji pri podpornem okolju za podjetništvo zasebni kapital zelo slabo zastopan.

Tezo T3 (Večina subjektov podjetniškega podpornega okolja deluje samo na področju startupov oziroma inovativnih podjetij) zavržemo, saj smo ugotovili, da ima samo 8 subjektov med člani oziroma inkubiranci samo start-up podjetja, 8 subjektov ima med člani oziroma inkubiranci start-up podjetja in običajna podjetja, pri 3 subjektih podjetniškega podpornega okolja pa samo bili člani samo običajna podjetja.

Menimo, da ima Slovenija veliko število subjektov podjetniškega podpornega okolja glede na svojo majhnost, vendar kvantiteta ni enako kvaliteti. Večina subjektov, ki se ukvarja s podporo start-upom, je bila ustanovljena s strani javnih institucij, predvsem občin. Pri tem se lahko vprašamo ali imajo vsi ti subjekti ustrezne kadre, saj je podpora start-up podjetjem za večino izmed njih samo ena izmed nalog, ki jih opravljajo. Zanima nas tudi ali in kako merijo učinkovitost podpore. Poleg tega je geografska porazdelitev subjektov problematična, saj so določene regije zelo zapostavljene.

\section{Zaključek}

Pri pregledu razširjenost subjektov podjetniškega podpornega okolja glede na regijo smo opazili, da obstajajo velike razlike glede števila subjektov po posameznih regijah. Predvsem 
je zaskrbljujoče zelo nizko število na Koroškem in Goriškem, ki že tako veljata za manj razviti regiji in sta tudi prometno slabo povezani z osrednjo Slovenijo, kjer se nahaja največ subjektov. Pri analizi števila subjektov podjetniškega podpornega okolja glede na vrsto ustanovnega kapitala (javni vs. zasebni) smo ugotovili, da je velika večina subjektov ustanovljena s strani javnih institucij, torej z javnim kapitalom. Tudi subjekti, ustanovljeni z zasebnim kapitalom, se večinoma financirajo prek prijav na javne razpise. To se mi zdi zaskrbljujejo, saj se zavedamo, da je nadzor učinkovitosti porabljenega denarja pri javnem kapitalu manjši in menimo, da bi Slovenija potrebovala vsaj nekaj zasebnih subjektov, ki bi dajali večji pomen učinkoviti rabi sredstev. Pri pregledu števila subjektov podjetniškega podpornega okolja glede na vrsto podjetij, ki jih podpirajo (start-upi ali običajna podjetja) smo ugotovili, da veliko subjektov dela tako z običajnimi podjetji kot start-upi. Zaradi posebnih potreb start-upov v primerjavi z običajnimi podjetji, taka organizacija ni optimalna. Vendar se moramo zavedati, da je Slovenija majhna in ima posledično manjše potrebe po podpornih subjektih za start-upe. Posledično delitev na subjekte, ki bi podpirali samo startupe, in subjekte za podporo običajnim podjetjem ne bi bila racionalna. Po drugi strani pa

Menim, da naloga podaja osnoven pregled subjektov podjetniškega podpornega okolja in je lahko v pomoč pri bolj poglobljenih analizah ter pripravi vprašalnikov za bolj poglobljeno raziskavo subjektov podpornega okolja.

Kot največjo omejitev raziskave bi navedla dinamičnost področja, saj se je v nekaj letih veliko spremenilo. Določeni subjekti, ki sem jih našla na seznamih v literaturi ne delujejo več, pojavili so se novi subjekti. Obstaja veliko različnih seznamov in na določeni točki se je potrebno ustaviti in končati z raziskovanjem. Poleg tega ni nujno, da vsi subjekti res izvajajo svoje poslanstvo $\mathrm{v}$ povezavi s podporo podjetjem, saj smo se zanašali na opise na spletnih straneh.

Na začetku je bila analiza zastavljena dosti širše in je vključevala več dejavnikov, vendar nam iz javno dostopnih virov (uporabljali smo spletne strani in AJPES) ni uspelo pridobiti dovolj zanesljivih podatkov. Analizirali smo število zaposlenih, kateri podatek smo v veliki večini pridobili iz AJPES-a. Vendar za coworking teh podatkov ni na voljo, saj niso zabeleženi v AJPES-u, ker niso poslovni subjekti. Pri inkubatorjih in tehnoloških parkih pa se pogosto pojavlja težava, da delujejo inkubatorji v sklopu tehnološkega parka ali kake druge institucije in ni razvidno, koliko zaposlenih dejansko dela v inkubatorju. Druga tema, ki smo naleteli na težave pri analizi je raziskava in primerjava storitev, ki jih nudijo subjekti podpornega okolja. $\mathrm{V}$ večini primerov imajo subjekti navedeno na svoji spletni strani, katere storitve nudijo, vendar se format prikaza teh storitev med različnimi subjekti zelo razlikuje in jih je težko primerjati.

Predlog za nadaljnje raziskovanje bi bil ugotoviti kakšne učinke subjekti podjetniškega podpornega okolja dosegajo glede na vložene vire. Tako bi lahko raziskali število zaposlenih in koliko finančnih virov porabijo kot vhodne podatke oziroma vire. Kot učinke bi lahko 
preverili število in vrsto izvedenih aktivnosti ter število in uspešnost podjetij, ki so jim subjekti podjetniškega podpornega okolja pomagali.

\section{Reference}

1. ABC ACCELERATOR. (2020, 29. februar). Pridobljeno na: https://abc-accelerator.com/

2. AJPES. (2020, 29. februar). Pridobljeno na: https://www.ajpes.si/

3. Allen, D.N. \& Rahman S. (1985). Small Business Incubators: A Positive Environment for Entrepreneurship. Journal of Small Business Management, 23 (3), 12-22.

4. Campbell, C. (1989). Change agents in the new economy: Business incubators and economic development. Economic Development Review (Schiller Park, III), 7 (2). 56-59.

5. Go:global Slovenia za prijavljene podjetnike na Start:up Slovenija. (2020, 29. februar). Pridobljeno na: http://www.rcikt.com/novice/goglobal-program-za-prijavljene-podjetnike-nastartup-slovenija/

6. Inkubator GEA College. (2020, 29. februar). Pridobljeno na: https://gea-college.si/inkubator-geacollege/

7. Inkubator Sežana. (2020, 29. februar). Pridobljeno na: https://inkubator.si/

8. Inkubator savinjske regije. (2020, 29. februar). Pridobljeno na: http://www.inkubatorsr.si/

9. KIKštarter. (2020, 29. februar). Pridobljeno na: https://kikstarter.si/

10. Lah, S. (2009). Podjetništvo. Pridobljeno na: http://www.impletum.zavodirc.si/docs/Skriti_dokumenti/Podjetnistvo-Lah.pdf

11. Ljubljanski univerzitetni inkubator. (2020, 29. februar). Pridobljeno na: https://lui.si/

12. Mrežni podjetniški inkubator Koroška. (2020, 29. februar). Pridobljeno na: www.mpikkoroska.si/si/

13. Mrežni podjetniški inkubator Ormož. (2020, 29. februar). Pridobljeno na: https://mpiormoz.si/mpi/

14. Mrežni podjetniški inkubator Rogaška Slatina. (2020, 29. februar). Pridobljeno na: https://www.inkubator-rs.si/

15. Pirnat, N. (2014). Startup ekosistem v Sloveniji. Pridobljeno na http://www.internetweek.si/pregled-startup-podpornega-okolja-v-sloveniji/

16. Podjetniški inkubator Kočevje. (2020, 29. februar). Pridobljeno na: https://www.inkubatorkocevje.si/

17. Podjetniški inkubator Kostel. (2020, 29. februar). Pridobljeno na: http://inkubator-kostel.si/

18. Podjetniški inkubator Perspektiva Postojna. (2020, 29. februar). Pridobljeno na: http://www.inkubator-postojna.si/si/

19. Podjetniški inkubator Podbreznik. (2020, 29. februar). Pridobljeno na: https://www.rcnm.si/podjetniski-inkubator/

20. Pomurski tehnološki park. (2020, 29. februar). Pridobljeno na: http://p-tech.si/

21. Pravilnik o vodenju evidence subjektov inovativnega okolja. Uradni list RS, št. 25/08 in 27/17. Pridobljeno na http://pisrs.si/Pis.web/pregledPredpisa?id=PRAV8195

22. Primorski Tehnološki Park. (2020, 29. februar). Pridobljeno na: https://www.primorski-tp.si/

23. Razvojni center za informacijske in komunikacijske tehnologije. (2020, 29. februar). Pridobljeno na: http://www.rcikt.com/ 
24. Rebernik, M., \& Jaklič, M. (2014). Start:up manifest: Slovenija, pripravljena na prihodnost 2014 $-2020+$. Pridobljeno na http://www.elektroniki.si/novi/forum/download.php?id=13045

25. RIC Bela Krajina podjetniški inkubator. (2020, 29. februar). Pridobljeno na: https://inkubatorbelakrajina.si/

26. Rožanc, N. (2019). Veliki seznam coworking prostorov v Sloveniji. Pridobljeno na: https://www.netokracija.si/veliki-seznam-coworking-prostorov-v-sloveniji-113319

27. Rubin, T. H., Aas, T. H. \& Stead, A. (2015). Knowledge flow in Technological Business Incubators: Evidence from Australia and Israel. Technovation, 41-42, 11-24. doi:10.1016/j.technovation.2015.03.002

28. SAŠA inkubator. (2020, 29. februar). Pridobljeno na: https://sasainkubator.si/

29. Socialni inkubator. (2020, 29. februar). Pridobljeno na: https://www.socialni-inkubator.si/

30. Štajerski tehnološki park. (2020, 29. februar). Pridobljeno na: https://www.stp.si/

31. Tehnološki park Ljubljana. (2020, 29. februar). Pridobljeno na: https://www.tp-lj.si/sl

32. Univerzitetni inkubator Primorske. (2020, 29. februar). Pridobljeno na: https://www.uip.si/

33. Univerzitetni inkubator Tovarna podjemov. (2020, 29. februar). Pridobljeno na: https://www.tovarnapodjemov.org/

34. Ustvarjalnik. (2020, 29. februar). Pridobljeno na: https://ustvarjalnik.org/

35. Zakon o podpornem okolju za podjetništvo (ZPOP-1). Uradni list RS, št. 102/07, 57/12, 82/13. Pridobljeno na http://pisrs.si/Pis.web/pregledPredpisa?id=ZAKO5073

\section{$* * *$}

Elvira Matko je univerzitetna diplomirana prevajalka za angleški in nemški jezik. Od leta 2012 dela na področju kakovosti $\mathrm{v}$ avtomobilski industriji. Trenutno je zaposlena $\mathrm{v}$ podjetju Treves d.o.o. in študira Menedžment kakovosti na Fakulteti za organizacijske študije v Nove mestu.

\section{Abstract: Analysis of Business Support Environment for Start-Ups}

Research Question (RQ): What is the extend of business support environment in Slovenia terms of geography, number of different entities and sources of financing?

Purpose: The purpose of our research is to establish the extend of Slovenia's business support environment (ecosystem) for start-ups. The research focuses on geographical areas, types of entities and sources of financing.

Method: First the existing literature and web pages of individual entities working in the area of business support environment were checked. A list of all entities was prepared and analysed with which activities they supported start-ups.

Results: The research showed that Slovenia's business support environment for start-ups is stronger in some geographical areas than others. In addition, the majority of business support entities are not specialized for specific needs of start-ups, they also support regular businesses which means their support is not ideal. The majority of business support entities was funded by public money and even private entities are mostly financed with money coming from public tenders.

Organization: We believe our research will help the business support environment identify critical areas that need to be strengthened thus enabling a better support in all growth-phases for start-ups.

Society: Economic activity and establishment of successful businesses greatly influence the success of society and its social environment. Successful businesses serve people as means of 
Revija za univerzalno odličnost / Journal of Universal Excellence,

Junij / June 2020, leto / year 9, številka / number 2, str. / pp. 183-199.

prosperous life and enable them to realize their potential. Start-up businesses have a great potential for growth and development.

Originality: In our opinion the originality of research lies in two aspects: it delivers an analysis of Slovenia's business support environment, including some new factors which gives a new view of the topic. On the other side the research identifies certain drawbacks of the current system that present difficulties for start-up owners.

Limitations/Future Research: Due to its broad scope, the research is limited only to Slovenia and its business support environment. In addition the data was gathered from websites and publications and was not checked personally for each entity.

Keywords: startup, support environment, support ecosystem, business, Slovenia, incubator, technology park, coworking.

Copyright (c) 2020 Elvira MATKO

\section{(c) $\underset{\mathrm{EY}}{(\mathrm{P})}$}

Creative Commons License

This work is licensed under a Creative Commons Attribution-ShareAlike 4.0 International License. 